Bol. Acad. peru. leng. 64. 2018 (73-85)

\title{
LA POESÍA DE JOSÉ MARÍA EGUREN: TRADICIÓN E INNOVACIÓN
}

\section{THE POETRY OF JOSÉ MARÍA EGUREN: TRADITION AND INNOVATION}

\author{
Marco Martos Carrera \\ Academia Peruana de la Lengua
}

\section{Resumen:}

La poesía de José María Eguren ha sido considerada alternativamente como simbolista o como modernista terminal. Frente a la revolución que significa la poesía de César Vallejo, la de nuestro vate elegido es considerada una poesía tradicional. El artículo procura mostrar cómo, conociendo bien la evolución literaria del género, Eguren se desliza hacia una modernidad absoluta que lo hace uno de los poetas más originales de la tradición en lengua española.

\section{Abstract:}

The poetry of José María Eguren has been considered alternatively as symbolist or as terminal modernist. As opposed to the revolution that the poetry of César Vallejo means, that of our chosen poet is considered a traditional poetry. This paper tries to show how, knowing well the literary evolution of the genre, Eguren moves towards an absolute 
modernity which makes him one of the most original poets of tradition in the Spanish language.

Palabras clave: poesía, Eguren, tradición, innovación.

Key words: poetry, Eguren, tradition, innovation.

Fecha de recepción:

Fecha de aceptación:
$02 / 08 / 2018$

$31 / 10 / 2018$

José María Eguren (1874-1942) es una figura destacada en el panorama de la literatura del Perú contemporáneo. Es un poeta fundador, uno que habla desde la orilla del silencio, alejado de las modas y oriflamas del momento. Como suele suceder, en el momento que escribía había formas y temas instalados en el gusto del lector que venían del pasado inmediato. Todavía escribían algunos de los románticos supérstites, como el propio Ricardo Palma que, según propia afirmación, tenía algunos suspirillos germánicos en su estro, y escribía, claro está, dentro de los moldes románticos; destaca también la figura antitética al propio tradicionista, Manuel González Prada, quien es, sin duda alguna, el primer poeta de nuestra modernidad. Pero el espacio literario (la calle, los teatros, los libros, los comentarios, el gusto) estaba colmado por la poesía de José Santos Chocano. Mientras González Prada escribía:

Un dolor jamás dormido, una gloria nunca cierta, una llaga siempre abierta es amar sin ser querido.

Corazón que siempre fuiste bendecido y adorado, tú no sabes iay! lo triste de querer sin ser amado. 
https://doi.org/10.46744/bapl.201802.004

A la puerta del olvido

llama en vano el pecho herido:

muda y sorda está la puerta;

que una llaga siempre abierta

es amar sin ser querido.

(Horta 2015 Tomo I: 261)

José Santos Chocano en Blasón, uno de sus poemas más conocidos, pergeñaba lo siguiente:

Soy el cantor de América autóctono y salvaje, mi lira tiene un alma, mi canto un ideal. Mi verso no se me colgado de un ramaje con un vaivén pausado de hamaca tropical... Cuando me siento Inca le rindo vasallaje al Sol, que me da el centro de su poder real; cuando me siento hispano y evoco el Coloniaje, parecen mis estrofas trompetas de cristal.

Mi fantasía viene de un abolengo moro;

Los Andes son de plata, pero el León es de oro; y las dos castas fundo con épico fragor.

La sangre es española e incaico es el latido; iy de no ser Poeta quizás yo hubiese sido un blanco Aventurero o un indio Emperador!

(Santos Chocano 1987: 138)

Cada uno de estos poemas tiene distintas excelencias. Venido del Romanticismo, conocedor del parnasianismo, González Prada discurre en admirables octasílabos sobre las dificultades del amor y Chocano en sus alejandrinos sonoros, desde el centro mismo del modernismo, con sus particulares acentos del Perú, nos da su visión del país, detenido en el pasado, como lo ha visto José Carlos Mariátegui. Ambos expresan en sus textos diferentes realidades, González Prada, las líricas del corazón, y 
Chocano, la realidad ideológica que vivía, elogiosa del mundo que pasó. Eguren es algo diferente, y diverso también al otro poeta que aparecería en esos años: Vallejo. Si en Chocano y en González Prada podemos encontrar ecos parnasianos, Eguren, con toda razón, puede vincularse más bien con el simbolismo de Verlaine, y un poco menos con el que representa Mallarmé. Eguren lleva a la práctica, algo que escribió en esos años un poeta chileno que alcanzaría luego gran prestigio: Vicente Huidobro, quien en 1916 se expresó sobre la necesidad de los poetas de no cantar a la rosa, sino de hacerla florecer en un poema. Con este solo hecho, con esta razón de ser, Eguren se coloca en el centro de la modernidad y es por eso que lo consideramos ya un clásico. A partir de él, y no antes, la poesía del Perú cobra ese derecho fundamental de ser en si misma un asunto de formas y no de contenidos, como lo sostenían de un modo teórico los llamados formalistas rusos. ¿De qué habla la poesía? Fundamentalmente de sí misma, diría años más tarde otro poeta, admirador por cierto de Eguren, Martín Adán; según él, la poesía está callada escuchando su propia voz. Eguren, en dos palabras, no se refiere a ninguna realidad existente antes de su escritura, sino que la inventando mientras pergeña sus versos. Y eso se advierte en toda su vasta producción poética que tiene todavía otra virtud: no tiene caídas. Y su poesía se enmarca, dentro de lo que genéricamente se la llamado «la herencia del simbolismo», lo que la vincula con grandes líricos del siglo XX como Eliot, Rilke, Yeats, Pasternak.

En uno de sus poemas más célebres, publicado en 1916, La niña de la lámpara azul, Eguren escribe:

En el pasadizo nebuloso, cual mágico sueño de Estambul, su perfil presenta destelloso la niña de la lámpara azul.

Ágil y risueña se insinúa Y su llama seductora brilla, Tiembla en su cabello la garúa De la playa de la maravilla. 
https://doi.org/10.46744/bapl.201802.004

Con voz infantil y melodioso

En fresco aroma de abedul, Habla de una vida milagrosa

La niña de la lámpara azul.

Con cálidos ojos de dulzura

$\mathrm{Y}$ besos de amor matutino,

Me ofrece la bella creatura

Su mágico y celeste camino.

De encantación en un derroche,

Hiende leda, vaporoso tul;

Y me guía a través de la noche

La niña de la lámpara azul.

(Eguren 2014: 91)

El poema nos atrapa por su encanto. Está escrito en cuartetos de rima abrazada, con un número de sílabas inusual en la tradición castellana: un decasílabo, generalmente considerado propio de los himnos, sin embargo Eguren lo utiliza para este poema de tono lírico. Se trata de una sutil innovación. En el texto hay una palabra de poco uso: leda que significa 'alegre' y una referencia a Estambul que, sin duda, es una marca de la escritura modernista subyacente en el estro de Eguren. Pero no hay mayores referencias que nos permitan situar el poema dentro de una realidad geográfica determinada. Hay quienes han pretendido ver en el texto una referencia a Lima, a su garúa. Bien puede ser o no ser. Este poema de Eguren es magnífico también porque permite señalar que poco importa el origen mismo de un poema, las razones por las que el poeta lo escribió, las referencias escondidas a una realidad, lo que interesa es la palpable inmediatez de las palabras, lo que ellas dicen y sugieren al lector que acude a ellas con sus propias vivencias. Es en ese encuentro que surge, que aparece, el sentido. No hay un sentido previo guardado en la cabeza del poeta, en una secreta gaveta de su pensamiento. El sentido o los sentidos está o están en las palabras, en sus recónditos significados, que van al encuentro de lo que sienten y piensan los lectores. En esa 
condición podemos opinar de las secretas fibras interiores que moviliza el texto de Eguren. En el poema está presente el principio femenino, en la delicada figura de la niña de la lámpara azul que guía a través de la noche al autor del poema. Y esa es la clave, a nuestro juicio de todo el texto, lo indispensable de lo femenino en los sueños de los hombres. Una digresión nos puede ser útil, para comprender bien el sentido de la frase. En la mayor parte de las religiones, el principio femenino forma parta de la deidad o de las deidades, como ocurre en los sistemas religiosos de la antigua Grecia y de Roma. En la religión cristiana que surge en un país en permanente conflicto, tal vez por esa razón tiene un Dios todopoderoso, enérgico, que actúa con las tablas de la ley, lo femenino estuvo ausente, hasta que en 1950 el papa Pío XII dio categoría casi divina a la Virgen María a la que imaginó ascendiendo en cuerpo y alma a los cielos. Es Carl Jung quien ha subrayado lo importante de esta modificación. En el plano ideal, la mujer, la madre en primer lugar, es una especie de auxiliar mágico en la vida de los hombres y así esta niña de la lámpara azul cumple ese hermoso papel. Una prueba indirecta del valor de esta afirmación es que este poema gusta a muchas personas que no tienen mayor información literaria, que no conocen a Eguren, pero se sienten tocadas porque se trata de una experiencia universal. De modo que la literatura, la poesía que preferentemente forma, logra en su magia de palabras adentrarse en algo universal: lo femenino que guía el camino de los hombres.

Veamos otro poema célebre de Eguren:

Los reyes rojos

Desde la aurora combaten dos reyes rojos con lanzas de oro.

Por verde bosque $\mathrm{y}$ en los purpurinos cerros vibra su ceño. 
https://doi.org/10.46744/bapl.201802.004

\author{
Falcones reyes \\ batallan en lejanías \\ de oro azulinas. \\ Por la luz cadmio, \\ airadas se ven pequeñas \\ sus formas negras. \\ Viene la noche \\ y firmes combaten foscos \\ los reyes rojos.
}

(Eguren 2014: 64)

Desde el punto de vista formal, el poema está conformado por cinco tercetos que tienen versos impares pentasílabos y versos pares octasílabos, sin rima. El texto usa algún neologismo como purpurinos y un arcaísmo como foscos. Usa otra palabra no frecuente, cadmio. Como en el poema anterior, cualquier interpretación resulta empobrecedora porque el texto se sostiene solo gracias a sus poderosas imágenes de dos combatientes incansables que prosiguen su batallar aunque llegue la noche. Estuardo Núñez, quien conoció a Eguren y ha sido uno de sus exégetas, solía decir en su casa de la calle Las Mimosas 155, en Barranco, que Eguren tenía en su casa de ese balneario, una imagen en madera, que colgaba en una habitación en la que efectivamente dos combatientes airados enarbolaban sus lanzas. Ahí estaban de la mañana a la noche, y es posible, añadía, que fueran la razón de ser del poema. No hay por qué dudar de la versión, pero tomada literalmente, empobrece el poema. Si el poema fuese un calco de la realidad, entonces estaría compitiendo, por ejemplo, con la fotografía o con el propio cuadro colgado en la sala. Y no se trata de eso. Las palabras dicen algo diferente de la propia imagen que podrían evocar. El cuadro colgado que forma parte de un decorado, tal vez convoque la mirada distraída de un visitante. Sobre el poema volvemos una vez y otra a entender a los combatientes, a esos reyes rojos, símbolo de todos los que luchan por una causa, de manera indesmayable, todo los días, todas las noches. Esos reyes rojos, cuyas banderías antagónicas no se explican en el texto, han creado una realidad propia, que compartida puede ser 
https://doi.org/10.46744/bapl.201802.004

entendida por todos los seres humanos. Mientras un niño puede apreciar el sentido de aventura en el permanente combate, un hombre en días de su senectud, tal vez disfrute el poema como una metáfora de toda la vida como un permanente desafío.

Veamos otro de los poemas más conocidos de Eguren:

\section{El duque}

Hoy se casa el duque Nuez; viene en chantre, viene el juez y con pendones escarlata florida cabalgata; a la una, a las dos, a las diez: que se casa el duque Primor con la hija de Clavo de Olor. Allí están, con pieles de bisonte los caballos de Lobo del Monte, y con ceño triunfante, Galo cetrino, Rodolfo montante. Y en la capilla está la bella, mas no ha venido el duque tras ella; los magnates postradores, aduladores al suelo el penacho inclinan; los corvados, los bisiestos dan sus gestos, sus gestos, sus gestos; y la turba melenuda estornuda, estornuda, estornuda. $\mathrm{Y}$ a los pórticos y a los espacios mira la novia con ardor ... con sus dos ojos topacios de brillor. $Y$ hacen fieros ademanes, nobles rojos como alacranes; concentrando sus resuellos 
https://doi.org/10.46744/bapl.201802.004

grita el más hercúleo de ellos:

¿Quién al gran Duque entretiene?...

iya el gran cortejo se irrita!

pero el duque no viene...

se lo ha comido Paquita.

Sin duda alguna, este es uno de los poemas más logrados de Eguren. Escrito de manera muy libre, con versos de sílabas variadas, guarda cierta relación con la poesía tradicional por sus ocasionales rimas, pero está escrito con una actitud muy moderna. Prevalece en sus líneas un humor sorprendente, parece a ratos un juego de niños y en otros una reflexión madura sobre las tensiones que acompañan a uno de los ritos más importantes en la vida de los seres humanos: el matrimonio. Pero lo más valioso del texto es el final: «El duque no viene... se lo ha comido Paquita» son los versos más audaces de la poesía peruana hasta ese momento. Vendrá luego Vallejo y será más atrevido. Estos versos tienen doble valor, son sorprendentes en sí mismos, rompen con ese clima de fiesta bufa instaurado en el poema con una alusión directa a un hecho trágico, lo inconmensurable de la muerte, su visita súbita que daña todo festejo, y de otro lado nos lleva al mundo de lo insólito, de lo inesperado, de lo atrevido. La poesía a lo largo de los siglos tiene su razón de ser en los ritmos acentuales, las rimas, las estrofas, tradicionalmente es el reino de lo previsible, esa es su música. Va creando una cierta expectativa en el lector que verso a verso se cumple. Pero la poesía tiene recurso: romper esa expectativa, romper el ritmo, instaurar el desorden, cosa que muy pocos poetas saben hacer. Y Eguren, que alcanzó a conocer la poesía de vanguardia, como bien se sabe, no solo por razones temporales, sino también por su espíritu curioso que sentía atracción por lo desconocido, lo hizo. «El duque no viene... se lo ha comido Paquita» es un claro antecedente de algunas de las frases más celebradas de Vallejo por su audacia expresiva, como aquella en la que dice: «¿Cóndores? Me friegan los cóndores». «En uno y en otro caso se trata de la irrupción de un nivel de la lengua, el cotidiano, en otro nivel, el lírico depurado, estimado por una tradición de siglos. Solo por este poema podemos aseverar que la poesía de Vallejo, tan representativa y profunda, puede también explicarse 
como un desarrollo de una audacia de José María Eguren. Paquita es la irrupción de la desdicha en un contexto feliz. Es el rumor de la vida que hace aparecer el dolor en el momento más inopinado.

En líneas generales, la poesía de Eguren expresa de un modo sesgado emociones, escogiendo símbolos y personajes que permanecen enigmáticos para los lectores. Es una lírica que, como la pintura impresionista, sugiere más que define, poesía del matiz más que de la rotundidad, de la neblina más que de la claridad, susurrada, bisbiseada, apenas dicha y, por lo tanto, poesía de la orilla del silencio, del misterio. Los textos funcionan como pequeños relatos, presentaciones de personajes que a ratos parecen salidos del teatro japonés o el de las marionetas. $\mathrm{El}$ autor no interviene en lo que hacen los personajes, los describe con apagada voz. La sugestión es el campo de Eguren, su razón de ser, su mayor originalidad. Haríamos mal, sin embargo, si considerásemos a Eguren como un poeta fuera del tiempo, portador de las eternas galas de la poesía en un mundo hostil. Hay numerosas evidencias en su propia biografía de un hombre que enfrenta con valentía y estoicismo las dificultades diarias de la vida y que se mostraba permeable a los sucesos del mundo. Así ocurre en su poema de 1929 Canción cubista:

Alameda de rectángulos azules.

La torre alegre

del dandy.

Vuelan

mariposas fotos.

En el rascacielo

un gallo negro de papel

saluda la noche.

Más allá de Hollywood, en tiniebla distante

la ciudad luminosa

de los obeliscos

de nácar. 
https://doi.org/10.46744/bapl.201802.004

\author{
En la niebla \\ la garzona \\ estrangula un fantasma.
}

Una vez más, Eguren construye un mundo de fantasía, solo que, esta vez, hay un elemento muy conocido y que es la Meca del celuloide: Hollywood. Sin duda, el cine era una actividad que lo atraía mucho. En el otro poema El duque Nuez, algunos críticos han creído ver en Rodolfo Montante al actor de cine de aquellos años Rodolfo Mondolfo. Como hemos visto, según nuestro parecer, el origen mismo del poema, su vínculo con la realidad, no es algo determinante en las realizaciones líricas de nuestro poeta, sino el nivel de sugerencia. En este texto, Hollywood es una realidad indiscutible, conocida por todos sus lectores. Con su propia técnica, Eguren disminuye la presencia de la ciudad del cine imaginando una vez más en la lejanía una ciudad diferente donde una garzona, neologismo del francés, estrangula un fantasma. De manera sorprendente, este poema se vincula con el mostrado antes del Duque Nuez. En ambos casos hay una irrupción de lo femenino como portador de la muerte. En el poema del duque, hay una descripción detenida del personaje que no podrá acudir a su boda por la acción de Paquita que se lo come. En el segundo caso, la garzona estrangula a un fantasma. La muerte, una vez más, como en toda la tradición occidental, tiene rostro de mujer. Freud imaginaba que los varones tenemos tres figuras femeninas primordiales en toda nuestra vida: la madre, la esposa o compañera y la muerte. Y también, en otras páginas, hablando de la sexualidad, dice que el niño, en lo que llama «la escena primigenia» tiene una percepción del lado agresivo de la relación íntima entre hombre y mujer, por alguna observación casual de lo que ocurre entre sus padres en la aparente soledad de las alcobas. Eso queda grabado en la mente del infante $y$, en el caso de los artistas, suele aparecer de una u otra manera en sus composiciones. Por supuesto, desconocemos qué ocurrió con Eguren en su infancia, respecto a la intimidad de sus padres, pero sí sabemos lo que dicen estos dos poemas. En uno, el novio no acude al matrimonio porque ha sido comido, tragado por Paquita. No sabemos más de esa Paquita; en el otro, una garzona, cuyo nombre no se dice, estrangula un fantasma. Las relaciones entre hombre y mujer terminan 
https://doi.org/10.46744/bapl.201802.004

en desdicha, parecen decirnos estos dos textos. Eguren, en sus poemas y en su vida, idealizó a la mujer, como ocurre en el poema La niña de la lámpara azul que hemos analizado en este artículo, y como puede verse en su correspondencia guardada celosamente en el Instituto Riva Agüero de Lima, pero se detuvo en el umbral de la admiración que, si bien le permitió escribir una poesía descollante, le dificultó formar una propia familia como, según consta, hubiera deseado. Sea como fuere, poco a poco Eguren va consiguiendo lectores, cada vez más entusiastas, cien años después de su aparición como vate. 


\section{BIBLIOGRAFÍA}

EGUREN, J. (2014). Poesías completas. Prólogo y notas de Marco Martos. Glosario de Martha Muñoz. Lima. Peisa.

HORTA, M. (Compilador). (2017). Poesía peruana. Antología 15542014. Ica. Biblioteca Abraham Valdelomar.

CHOCANO, J. (1987). Obras escogidas. Lima. Oxy.

HIGGINS, J. (2006). Historia de la literatura peruana. Lima. Universidad Ricardo Palma.

KOHUT, K. y MORALES SARAVIA, J. (1998). Editores. Literatura peruana boy. Frankfurt. Publicaciones del Centro de Estudios Latinoamericanos de la Universidad de Eichstatt. 